Н.Е. Козлов. - Мичуринск: 2012. - 23 с.

3. Седов Е.Н. Программы, методы, приемы селекции яблони, их развитие и совершенствование. / Е.Н. Седов. // Вавиловский журнал генетики и селекции. - Т.17, №3, 2013. - C.487-498.

DOI 10.18699/GPB2020-113

\title{
Исследование мутагенного эффекта фосфемида на генотипах яч- меня по полевой всхожести семян и разнообразию мутаций
}

Тетянников Н.В. ${ }^{l}$, к.с.-х.н., н.с.; Боме H.A. ${ }^{2}$, д.с.-х.н., профессор; Вайсфельд Л.И. ${ }^{3}$, главный спещиалист.

${ }^{I}$ ФГБНУ «Всероссийский селекиионно-технологический институт садоводства и питомниководства», Москва, Россия, tetyannikovnv@уа.ru;

${ }^{2}$ ФГАОУ ВО «Тюменский государственный университет», Тюмень, Россия, bomena@mail.ru;

${ }^{3}$ Институт биохимической физики им. Н.М. Эмануэля Российской Академии наук, Москва, Россия, liv11@yandex.ru.

В статье показана возможность использования химического мутагена фосфемида для расширения генотипического разнообразия ячменя. Определена реакиия изучаемых образиов на обработку мутагеном по полевой всхожести семян. Получены мутантные популяции, различающиеся по частоте и спектру мутаций. Выделены перспективные формы ячменя, которые могут быть использованы в качестве исходного материала в селекиионных программах.

Ключевые слова: ячмень, индуцированные мутации, мутационная селекиия, ценный признак, химический мутаген.

\section{Research of the mutagenic effect of phosphemide of barley genotypes on field germination of seeds and the variation of mutations}

Tetyannikov N.V.' ${ }^{1}$, Bome N. A. ${ }^{2}$, Weisfeld L.I. ${ }^{3}$.

${ }^{1}$ All-Russian Horticultural Institute for Breeding, Agrotechnology and Nursery, Moscow, Russia.

${ }^{2}$ University of Tyumen, Tyumen, Russia.

${ }^{3}$ Emanuel Institute of Biochemical Physics of Russian Academy of Sciences, Moscow, Russia.

In article was presented the possibility of using of the chemical mutagen phosphemide for expansion of the genotypic diversity of barley. The reaction of the studied samples to treatment with a mutagen on the field germination of seeds was determined. Mutant populations differing in the frequency and spectrum of mutations were obtained. Promising forms of barley that can be used as starting material in breeding programs were highlighted. 
Keywords: barley, induced mutations, mutational selection, utility character, chemical mutagens.

Роль индуцированного мутагенеза в селекции сельскохозяйственных культур достаточна велика. Использование мутагенных агентов обеспечивает расширение генетической изменчивости количественных признаков растений, за счет образования новых неизвестных аллелей, способствующих созданию ценного исходного материала для селекции $[1,2]$.

Согласно сведениям, приведенным Jankowicz-Cieslak J. и др. (2017), ячмень занимает второе место, после риса по числу официально зарегистрированных мутантных сортов (свыше 280). Отмечается, что применение химических мутагенов дает больший выход полезных мутаций, чем применение физических факторов [3]. При этом наибольший результат наблюдается в улучшении морфологических признаков и биологических свойств, устойчивости к абиотическим и биотическим стрессам, увеличении качества и продуктивности растений [4].

В настоящее время развитие мутационной селекции связано с поиском новых агентов, обладающих высокой мутагенной активностью, и изучением специфичности их действия на различные сельскохозяйственные культуры. Для ячменя таким мутагеном является фосфемид (ди-(этиленимид)пиримидил-2-амидофосфорной кислоты).

Материал и методы исследования. С целью изучения мутагенного эффекта фосфемида нами были отобраны три образца ячменя по результатам комплексной оценки в коллекционном питомнике, различавшихся по принадлежности к ботанической разновидности и эколого-географическому происхождению: Зерноградский 813 (к-30453, Россия, var. erectum), Dz02-129 (к22934, Эфиопия, var. nigripallidum), C.I. 10995 (к-30630, Перу, var. sinicum). Сухие семена обрабатывали водным раствором мутагена в концентрациях $0,002 \%\left(2 \cdot 10^{-3} M\right)$ и $0,01 \%\left(1 \cdot 10^{-2} M\right)$, при экспозиции 3 часа, с последующим промыванием в проточной водопроводной воде в течение 40 мин. Контролем служили семена, выдержанные в дистиллированной воде.

Полевое исследование (2016-2018 гг.) проведено на экспериментальном участке биостанции «Озеро Кучак» Тюменского государственного университета. Почва окультуренная дерново-подзолистая, супесчаная. Количество семян каждого образца - 300 шт. В первом поколении $\left(\mathrm{M}_{1}\right)$ высевали по 25 семян (повторность 4-кратная); во втором $\left(\mathrm{M}_{2}\right)$ и третьем $\left(\mathrm{M}_{3}\right)$ поколениях - семьями по 20 шт. на делянках с учетной площадью $1 \mathrm{~m}^{2}$.

Результаты и их обсуждение. Информативным критерием реакции ячменя на мутагенную обработку является полевая всхожесть семян. В первом поколении $\left(\mathrm{M}_{1}\right)$ в контроле этот показатель у сорта Зерноградский 813 составил 68,0 \%, Dz02-129 - 63,0 \%; C.I. 10995 - 76,0 \%. Достоверное снижение всхожести отмечено у сорта Зерноградский 813 на 42,0 \%, а также у Dz02-129 на 24,0 \% в опытном варианте с концентрацией $0,01 \%$. Образец 
C.I. 10995 существенных различий с контролем не продемонстрировал (рисунок).

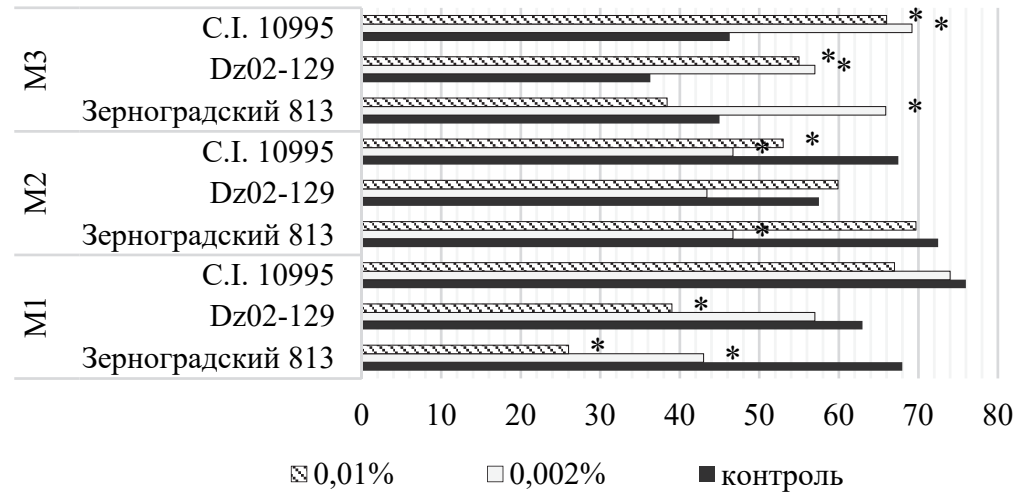

Полевая всхожесть семян, \%.

Примечание: *- различия достоверны при сравнении с контролем при $\mathrm{P}<0,05$.

Рисунок. Влияние различных концентраций фосфемида на полевую всхожесть семян ячменя в трех мутантных поколениях $\left(\mathrm{M}_{1}, \mathrm{M}_{2}, \mathrm{M}_{3}\right)$.

Схожая тенденция в опытных вариантах прослеживалась и во втором поколении $\left(\mathrm{M}_{2}\right)$, так достоверные различия с контролем отмечены у образца из Перу при двух концентрациях и у сорта Зерноградский 813 при концентрации $0,002 \%$. В М3 при прорастании семян в крайне неблагоприятных условиях получены низкие показатели всхожести в контроле (Зерноградский 813 - 45,0 \%; Dz02-129 - 36,3 \%, C.I. 10995 - 46,3 \%). В вариантах с фосфемидом отмечено статистически значимое увеличение всхожести у сорта Зерноградский 813 при концентрации 0,002 \% (на 20,9 \%), у образцов из Эфиопии и Перу при двух концентрациях (на 18,7-22,9 \%). Полученные данные позволяют предположить о повышении толерантности растений мутантных популяций к стресс-факторам в результате жесткого отбора под действием мутагена.

Частота и спектр индуцированных мутаций имеет прямое практическое значение при использовании химических мутагенов в селекционной работе. Всего нами было проанализировано 3031 растений, в том числе 2870 из семян, обработанных фосфемидом, относящихся к 286 семьям (потомство отдельных растений $\mathrm{M}_{1}$ ). Начиная с поколения $\mathrm{M}_{2}$ отбирали растения с видимыми отличиями от исходных форм, общий процент которых составил 7,2 $\%$. В варианте с концентрацией $0,002 \%$ отобрано 100 растений $(6,9 \%)$, варианте $0,01 \%$ - 117 (8,2 \%), по семьям - 21,0 \% и 18,2\%, соответственно. Среди образцов максимум изменений отмечен у C.I. 10995 (44,6 \% семей или 
48,9 \% растений).

$\mathrm{B}$ поколении $\mathrm{M}_{2}$ в широком спектре наряду с нежелательными признаками (изменения в строении колоса, булавовидность, ветвистость, искривления остей и выступа колосового стержня), выделены формы, перспективные для селекционного использования (раннеспелые, низкорослые, устойчивые к полеганию, с восковым налетом на соломине, крупноколосые); также в ряде семей обнаружены мутации, связанные с изменением ботанической разновидности, окраски колоса и остей. Стоит обратить внимание на специфичность в индуцировании различных типов мутаций в зависимости от генотипа и концентрации раствора мутагена. Только у образца С.I. 10995 (var. sinicum) наблюдалось появление других разновидности (var. pallidumи var. nutans); в варианте с 0,01 \% обработкой отобрано 19,7 \% растений, при $0,002 \%-2,0 \%$. Изменение окраски колоса и остей, в сочетании с интенсивным восковым налетом на соломине отмечено только у образца Dz02-129 (к22934, var. nigripallidum), что предположительно может объясняться мутацией в гене $B l p l$, отвечающим за черную окраску зерновки. В работе О.Ю. Шоевой с соавторами показано, что доминантные аллели $B l p l . b(B), B l p l . M b$ $\left(B^{m b}\right), B l p l . g\left(B^{g}\right)$ способны определять насыщенный черный, темный и серый цвет зерновки [5]. Изменениями в строении колоса характеризовались 12 растений из 10 семей сорта Зерноградский 813. У многих мутантов, отобранных в $\mathrm{M}_{2}$, наблюдалась константность в проявлении признаков в $\mathrm{M}_{3}$.

Заключение. Таким образом, на основании полученных данных, можно заключить, что специфичность фенотипического проявления индуцированных мутаций связана с генотипическими особенностями образцов ячменя, оказывающих влияние на мутационную изменчивость. Показана зависимость полевой всхожести семян в $\mathrm{M}_{1}$ и $\mathrm{M}_{2}$ от концентрации мутагена. В $\mathrm{M}_{3}$ семена мутантных популяций в отличие от контрольных, были более устойчивы к температурному и водному стрессам, и обеспечили относительно высокую полевую всхожесть. Высокая концентрация фосфемида 0,01 $\%$ способствовала большему выходу растений с изменениями. Максимальным числом изменений, выявленных в $\mathrm{M}_{2}$ и подтвержденных в $\mathrm{M}_{3}$, характеризовался C.I. 10995 (к-30630), низкой мутабильностью отличался сорт Зерноградский 813 (к-30453).

\section{Списоклитературы}

1. Oladosu Y. Principle and application of plant mutagenesis in crop improvement: a review / Y. Oladosu, M.Y. Rafii, N. Abdullah, G. Hussin, A. Ramli, H.A. Rahim, G. Miah, M. Usman // Biotechnology \& Biotechnological Equipment, Vol. 30 (1), 2016. - Pp. 1-16, DOI: $10.1080 / 13102818.2015 .1087333$.

2. Raina A. Role of Mutation Breeding in Crop Improvement - Past, Present and Future / A. Raina, R.A. Laskar, S. Khursheed, R.Amin, Y. R. Tantray, K. Parveen, S. Khan // Asian Research Journal of Agriculture, №2 (2), 2016. - Pp. 1-13.

3. Jankowicz-Cieslak J. Mutagenesis for Crop Breeding and Functional Genomics / J. Jankowicz-Cieslak, C. Mba, B.J. Till // Biotechnologies for Plant Mutation Breeding, 2017. 
- Pp. 3-21. DOI: 10.1007/978-3-319-45021-6_1.

4. Jankowicz-Cieslak J. Chemical Mutagenesis of Seed and Vegetatively Propagated Plants Using EMS / J. Jankowicz-Cieslak, B.J. Till // Current Protocols in Plant Biology, Vol. 1 (4), 2016. - Pp. 617-635. DOI: 10.1002/cppb.20040.

5. Шоева, О.Ю. Гены, контролирующие синтез флавоноидных и меланиновых пигментов ячменя / О.Ю. Шоева, К.В. Стрыгина, Е.К. Хлесткнина // Вавиловский журнал генетики и селекции, №22 (3), 2018. - С. 333-342.

DOI 10.18699/GPB2020-114

\section{Результаты изучения новой низкопентозановой популяции озимой ржи в условиях Красноярского края}

Тимина М.А.*І, к.с.-х.н., в.н.с.; Кобылянский В.Д. ${ }^{2}$, д.б.н., г.н.с.; Солодухина О.В. ${ }^{2}$, д.б.н., в.н.с.

${ }^{1}$ Федеральный исследовательский цчентр «Красноярский научный цуентр СО РАН» Красноярский научно-исследовательский институт сельского хозяйства, Красноярск, Россия;

${ }^{2}$ Федеральный исследовательский цуентр Всероссийский институт генетических ресурсов растений им. Н.И.Вавилова, Санкт-Петербург, Россия.

*e-mail: marina3912@mail.ru

В условиях Красноярского края изучены хозяйственные и биологические свойства новой низкопентозановой популяции озимой ржи (селекционный номер 51/14). Образец 51/14 продемонстрировал хорошую зимостойкость, превосходит районированнье сорта по продуктивности, отличается укороченной прочной соломиной, высокой устойчивостью к полеганию, повышенной крупностью зерна. В 2019 году образец 51/14 принят на Государственное испьтание с названием Арга.

Ключевые слова: озимая рожь, водорастворимые пентозаны, продуктивность, зимостойкость, устойчивость к полеганию.

\section{Results of studying a new low-pentosan population of winter rye in the con- ditions of Krasnoyarsk Region}

M.A. Timina ${ }^{1}$, V.D. Kobylyansky ${ }^{2}$, O.V. Solodukhina ${ }^{2}$

${ }^{1}$ Krasnoyarsk Agricultural Research Institute, Federal Research Center "Krasnoyarsk Scientific Center of the SB of the RAS”, Krasnoyarsk, Russian Federation.

${ }^{2}$ N.I. Vavilov Institute of Plant Genetic Resources, Sankt-Petersburg, Russian Federation.

In the conditions of the Krasnoyarsk region, the economic and biological properties of the new low-pentosan winter rye population were studied (selection 